Izvorni naučni članak

UDK: 711.6(497.11)

316.334.56:614(497.11)

ID: 212261644

\author{
Nikola Samardžić \\ Redovni profesor, Odeljenje za istoriju \\ Filozofski fakultet, Univerzitet u Beogradu \\ Čika Ljubina 18-20, 11000 Beograd, Srbija \\ nsamardz@f.bg.ac.rs
}

\title{
URBANI JAVNI PROSTOR I ZDRAVSTVENA KULTURA U BEOGRADU*
}

\begin{abstract}
Following the general urbicide policy from the last decade of the $20^{\text {th }}$ century, urban and social degradation of Belgrade is revealing new tendencies and features during the actual 2000s: institutional incompetence and corruption, collapse of health care system and public health generally, media criminalization of doctors, professors of medicine and medical staff, obliteration of cultural institutions, pressures on small and medium business initiatives as strongholds of labor and capitalist ethics, public promotion of unhealthy lifestyle, public and institutional tolerance (even support) of extremism directed against minority groups.

Belgrade is facing complex challenges of the urban, suburban and rural mentalities that still pervade in the city core. The issue of healthy living and taking care of public spaces can be directly linked to all of the important challenges of the transition to the actual state of political and economic autarchy.

Statistically, Serbia is predominantly urban. The percentage of urban population increased from $52.3 \%$ in 1999 to $58 \%$ in 2003. Recent urbanization, however, has been sporadic. Serbia is currently the oldest European society, with the smallest demographic development potentials, and still among the poorest and least developed European countries. GDP per capita in 2013 was 2.8 times lower than the EU average. The violent Yugoslav disintegration has slowed the economic and social development of each republic individually. Slovenia's GDP per capita is currently at $\$ 22,700$, Croatian is at $\$ 13,500$, Serbian is at $\$ 5,900$ (less than Montenegro, which is about $\$ 7,000$ ). The total external debt of the former republics has nominally increased tenfold compared to the former Yugoslavia, but substantially has grown to about five times higher. All
\end{abstract}

\footnotetext{
* Rad predstavlja rezultat naučno-istraživačkog projekta br. 177009: „Modernizacija zapadnog Balkana”, finansiranog od strane Ministratsva prosvete, nauke i tehnološkog razvoja Republike Srbije.
} 
important parameters of economic, political, and social performance have remained low in comparison to the EU standards: operational efficiency, freedoms and speed of exchange of capital, goods, services, people and ideas, freedom of expression, individual, minority and cultural freedom. Real consumption per capita, which includes health and education services, lower by almost two and a half times the EU average. In consumption sector stagnation is noticeable compared to 2008.

Serbia is also at the European bottom in relation to the attention devoted to the regulation of public spaces, and the environment generally, consequently to the public health as well. In this respect it is similar to the Third World or BRIC governments. The total annual damage caused by air pollution is estimated to be between $€ 0.45$ billion and $€ 1.37$ billion, or between $1.8 \%$ and 5.5\% of GDP. According to the National Environmental Strategy the annual damage from inadequate waste management is estimated to be between 98 and 276 million $€$ (or between $0.4 \%$ and $1.1 \%$ of GDP). The energy sector is the largest polluter in Serbia. Serbia in 2005 produced $65.5 \%$ of its electricity by burning coal. About $39 \%$ of households in Serbia uses coal as a primary source of heat, $33 \%$ use electricity, $7 \%$ wood, $7 \%$ natural gas and $14 \%$ the Heating Plant energy. Forty-five cities have remote heating systems, and they also are energy inefficient. Production and distribution losses exceed $20 \%$ of production. Power generator facilities produce huge surpluses of waste materials and endanger the environment polluting water, air and soil. Landfills in Serbia contain about 170 million tons of ash, which covers an area of 1,800 ha.

The care of public spaces in service of the public health is not exhausted by the environment protection. Public health is a factor of social cohesion. Public spaces are also a framework and instrument of social cohesion. Along with the economy or public policy, public health and public spaces belong to the general framework of investment, of the private and public sector development, public-private partnerships, public order and the democratization of social relations. Cities are driving forces of modernization and democratization. Over the last decade, for the first time in history, the cities encompassed the larger part of the total global population. Cities have taken primacy in all important social, economic and cultural activities. Cities occupy only about $2 \%$ of habitable land, but calculations estimate that by mid- $21^{\text {st }}$ century cities will be populated with up to $80 \%$ of the total world population. Cities consume $75 \%$ of world's energy and account for $80 \%$ of $\mathrm{CO}_{2}$ emissions.

Democratization of public space takes place not only in individual cities, but also in the process of European integration. In the quest for the realization of "four freedoms" of movement and exchange of people, goods, services and ideas, European integration has provided the most effective and democratic institutional framework. Public health and environmental protection were given an important place in different sectors of European administration, with concerns about the interaction of interests and activities of the sectors of the economy and finance. Public health is one of the priorities of the European agenda. Particular attention is paid to the prevention of disease, promotion of healthy living, and fostering the decision-making in local communities.

Concern about the spread of freedom and respect for the culture of public health is one of the most important activities of democratic policies, and requires open and competent coping with the challenges and obstacles. The EU has established a complex and dynamic common space rising living standards, and highly developed the public health institutions, environmental protection and healthy cities culture. The rapid 
economic growth has opened up questions of increasing social disparities. Differences became more pronounced after the entry of Eastern European countries into the EU in 2004 and 2007. European integration has become the impetus to the development of cities that have languished along the Cold War peripheries, getting another chance in the general context of European development, as the choking boundaries have been almost suddenly dismissed (Stettin, Berlin, Dresden, Prague, Plzen, Vienna, Bratislava, Trieste).

Traditionally predominantly rural or nomadic, Southeastern Europe was considering the cities and their cultures as alien and incidental, and urban life as deviant in relation to the real or imaginary values of the ancestors and their institutions. Similar mentalities have been rooted even in the Balkan cities themselves, as consequences, or sources of urban autarchy. In contrast with such reality, the improvement of living conditions depending on the development of the complex structure of public institutions and the public role of science, experts and non-governmental sectors, in other words, the efficiency of the health sector, the infrastructure, and the urban public space improvement. Urban History of South-Eastern Europe still awaits interesting and valuable answers in this respect:

- the way the cities were adapting to the geo-climate conditions, the resources of water, food, energy and labor;

- how the urban everyday life, urban institutions or lack of institutions affected the public health;

- whether the urban planning included the improvement of social contacts, thereby, indirectly and public health

- the issue of clean and waste water, etc.

- the way the cities were facing the diseases, especially these associated with the urban development?

- the challenges of malnutrition, poverty and social inequality;

- the investments in basic health care, access and preservation of clean water, waste disposal, public hygiene, recreation and entertainment, transportation and communication, energy, regulation of banks and parks, child care;

- questions related to the cultural anthropology and urban poverty;

- In the previous context, the issues of role and fate of ethnic communities, enclaves and ghettos.

The current urban health crisis stems in part from a growing gap between fiscal resources and needs. Increasing demand for health services, a large number of migrants are poor and still upcoming into the urban areas, bringing along the health issues related to poverty. Cities are, functionally, the centers of medical knowledge, advanced research and its application, but also the rapid spread of infectious diseases. History of modern public health is essentially associated with urbanization. In modern cities, the majority of social epidemic is related to urban life, primarily affecting the poor. Cities are characterized by population density, social diversity, complexity and instability, individual and group conflicts, migration and rapid social permeability. 
Ključne reči: javno zdravlje, životna sredina

$\mathrm{Ne} \mathrm{MeSH}$ :Beograd, javni prostor, urbicid

Key words: public health, environment

Non MeSH: Belgrade, public space, urbicide

$\mathrm{U}$ toku poslednje decenije XX veka urbicid je bio jedan od pratećih procesa jugoslovenske nasilne dezintegracije. Nakon 2000. postajalo je očigledno da društvena struktura i slabe institucije ohrabruju tendencije iz prehodnog vremena. $U$ toku poslednjih relativno mirnih 15 godina degradacija Beograda je ušla u nove tokove i dobila nova svojstva: korupcija i nekompetencija institucija, urušavanje zdravstvenih ustanova i javnog zdravlja, medijska kriminalizacija lekara, profesora medicine i medicinskog osoblja, zatiranje kulturnih institucija, gušenje male i srednje poslovne inicijative kao uporišta radne i kapitalističke etike, javna promocija nezdravog života, javna i institucionalna tolerancija, nekad i podrška ekstremizma usmerenog prema manjinskim grupama.

Beograd se suočava sa složenim izazovima urbanih, prigradskih i ruralnih oblika života koji se i dalje prožimaju u najužim gradskim jezgrima. Pitanje zdravog života i brige o javnim prostorima može se neposredno vezati za sve važne izazove političke i ekonomske autarhije.

Statistički posmatrano, Srbija je pretežno urbana. Procenat gradskog stanovništva je porastao s 52,3\% u 1999. na 58\% u 2003. Urbanizacija je, međutim, i u najnovijem vremenu bila stihijska. Srbija je trenutno najstarije evropsko društvo, istovremeno s najmanjim demografskim potencijalima. Među najsiromašnijim je i najnerazvijenijim evropskim državama. BDP po stanovniku je 2013. bio 2,8 puta niži od proseka Evropske unije. Jugoslovenska dezintegracija usporila je ekonomski i društveni razvoj svih republika pojedinačno. Slovenački BDP po stanovniku trenutno iznosi $22.700 \$$, hrvatski 13.500 , srpski 5.900\$ (manji od crnogorskog, koji je oko 7.000\$). Ukupan spoljni dug bivših republika nominalno je udesetostručen u odnosu na nekadašnji jugoslovenski, a realno je oko pet puta veći. Slični su svi parametri ekonomskih, političkih i društvenih performansi: efikasnost poslovanja, sloboda i brzina razmene kapitala, roba, usluga, ljudi i ideja, sloboda javnog izražavanja, individualne, manjinske ili kulturne slobode. Stvarna potrošnja po stanovniku, koja uključuje zdravstvene i obrazovne usluge, niža je za skoro dva i po puta od EU proseka. U domenu potrošnje je primetna stagnacija u odnosu na 2008.

Briga o uređenju javnih prostora, o javnom zdravlju i životnoj sredini takođe je na evropskom začelju, i u tom pogledu je Srbija sličnija zemljama Trećeg sveta. Ukupna godišnja šteta prouzrokovana zagađenjem vazduha je procenjena na između 0,45 milijardi i 1,37 milijardi €, ili između 1,8\% i 5,5\% BNP. Prema Nacionalnoj strategiji zaštite životne sredine procenjuje se da je godišnja šteta od neadekvatnog manipulisanja otpadom između 98 i 276 miliona $€$ (ili između 0,4\% i 1,1\% BNP). Energetski sektor je najveći zagađivač u Srbiji. Srbija je 2005. proizvela 65,5\% električne energije 
sagorevanjem lignita. Oko 39\% domaćinstava u Srbiji koristi ugalj kao osnovni izvor zagrevanja, 33\% koristi električnu energiju, 7\% drvo, 7\% prirodni gas, a svega $14 \%$ energiju iz toplana. Četrdeset pet gradova ima sisteme toplana, koji su energetski neefikasni. Proizvodni i distributivni gubici prelaze $20 \%$ proizvodnje. Postrojenja za proizvodnju energije proizvode ogromne viškove otpadnog materijala i ugrožavaju životnu sredinu zagađenjem i zagrevanjem vode, vazduha i tla. Deponije u Srbiji sadrže oko 170 miliona tona pepela, koji pokriva oblast od 1.800 ha. [1]

Briga o javnim prostorima u službi javnog zdravlja ne iscrpljuje se brigom o životnoj sredini. Javno zdravlje je činilac društvene kohezije. Javni prostori takođe su okvir i instrument društvene kohezije. Uporedo sa ekonomijom ili javnom politikom, javno zdravlje i javni prostori spadaju u opšte uslove ulaganja, razvoja privatnog i javnog sektora, privatno-javnog partnerstva, javnog reda i demokratizacije društvenih odnosa. Gradovi su pokretačka snaga modernizacije i demokratizacije. Tokom poslednjih decenija, u gradovima, prvi put u istoriji, obitava veći deo ukupne globalne populacije. Gradovi su preuzeli primat u svim važnim društvenim, ekonomskim i kulturnim aktivnostima. Gradovi zauzimaju svega oko $2 \%$ nastanjivog kopna, ali proračuni najavljuju da će do sredine XXI veka gradove nastanjivati do $80 \%$ ukupnog svetskog stanovništva. Gradovi troše $75 \%$ svetske energije i učestvuju sa $80 \%$ u emisiji $\mathrm{CO}_{2}$.

Demokratizacija javnog prostora odvija se ne samo u pojedinačnim gradovima, nego i u procesu evropske integracije. U traganju za ostvarenjem „četiri slobode”, sloboda kretanja razmene ljudi, roba, usluga i finansijskog kapitala (Rimski ugovori, 1957), evropska integracija je obezbedila najefikasniji i najdemokratskiji institucionalni okvir. Javno zdravlje i zaštita životne sredine dobili su važno mesto u različitim sektorima evropske administracije, uz brigu o interakciji interesa i delovanja sa sektorima ekonomije i finansija. Javno zdravlje je među prioritetima evropske agende. Naročita pažnja poklanja se prevenciji bolesti, promociji zdravog života, ili podsticanju odlučivanja u lokalnim zajednicama. [2]

Kultura javnog zdravlja u kontekstu poštovanja i širenja sloboda, jedna je od najvažnijih aktivnosti demokratske javne politike, koja iziskuje otvoreno i kompetentno suočavanje sa izazovima i preprekama. EU je izgradila izuzetno složen i dinamičan jedinstven prostor rasta životnog standarda, i razvila institucije i kulturu brige o javnom zdravlju, time i brige o zaštiti životne sredine i zdravih gradova. Ubrzan ekonomski rast otvarao je pitanja rastućih socijalnih razlika. Razlike su postale izrazitije nakon ulaska istočnoevropskih država u EU 2004. i 2007. Evropska integracija postala je i podstrek razvoju gradova koji su tavorili na strateškim hladnoratovskim periferijama dobili su novu priliku u kontekstu opšteg evropskog razvoja, pošto su granice koje su ih gušile najednom nestale (Šćećin, Berlin, Drezden, Prag, Plzen, Beč, Bratislava, Trst).

Tradicionalno pretežno ruralna ili nomadska, Jugoistočna Evropa je gradove doživljavala i tumačila kao tuđinske i incidentne pojave, a gradski život kao devijantan u odnosu na stvarne ili izmišljene vrednosti predaka i njihovih institucija. Taj 
mentalitet ukorenio se u samim gradovima, čemu su doprineli stihijska urbanizacija, autarhija i siromaštvo. U kontrastu s takvom stvarnošću, unapređenje životnih uslova u zavisnosti je od razvoja složene strukture javnih ustanova i javne uloge nauke, stručnjaka ili nevladinog sektora, drugim rečima od efikasnosti zdravstvenog sektora, od infrastrukture, od unapređenja urbanog javnog prostora. Urbana istorija Jugoistočne Evrope i dalje traga za zanimljivim i vrednim odgovorima u tom smislu:

- kako su se gradovi prilagođavali geoklimatskim uslovima, resursima vode, hrane, energenata ili radne snage;

- kako su urbana svakodnevica, njihove institucije ili nedostatak institucija delovali na javno zdravlje;

- da li se urbanim planiranjem obraćala pažnja na unapređenje socijalnih kontakata, time, posredno i javnog zdravlja;

- pitanja čistih i otpadnih voda i sl;

- s kakvim su se bolestima, naročito s bolestima nastalim u okolnostima urbanog razvoja, gradovi suočavali u svojoj prošlosti?

- kako su se suočavali sa izazovima bolesti, loše ishrane, siromaštva i društvene nejednakosti?

- u kojoj meri se ulagalo u osnovnu zdravstvenu zaštitu, pristup i očuvanje čiste vode, odlaganje otpadnih materija, javnu higijenu, rekreaciju i zabavu, transport i komunikacije, energetiku, uređenje obala i parkova, brigu o deci?

- pitanja antropologije i kulture urbanog siromaštva, uloga i sudbina etničkih zajednica, enklava i geta. [3]

Tekuća urbana zdravstvena kriza delimično potiče od sve većeg raskoraka između fiskalnih izvora i potreba. Veliki broj siromašnih doseljava se u gradske oblasti donoseći sobom i zdravstvene probleme vezane za siromaštvo. Time se povećala potreba za zdravstvenim uslugama. [4] Gradovi su, funkcionalno, centri medicinskog znanja , naprednih istraživanja i njihove primene, ali i brzog širenja zaraznih bolesti. Istorija modernog javnog zdravlja je svojom suštinom povezana sa urbanizacijom i razvojem modernih gradova. U savremenim gradovima većina društvenih epidemija je vezana za gradski život, a pre svega pogađaju siromašne slojeve. Gradovi su karakteristični po gustini naseljenosti, društvenoj raznolikosti, složenosti i nestabilnosti, individualnim i grupnim sukobima, migracijama i brzom društvenom propustljivošću.

Javni prostor ima važnu ideološku ulogu u demokratskim zajednicama. Od antičkog vremena javni prostor koristio se kako bi se vodili javni i privatni poslovi, održavale se pravne rasprave, bili su tržnice i jezgra društvenog života. Javni prostori su i mesta susreta stranaca s domaćim građanstvom. Javni prostori učestvuju u posredovanju između države i društva. Struktura okupljenih u takvim aktivnostima ukazivala je na stepen demokratizacije, u smislu inkluzije. Publika u antičkim javnim prostorima bila je brižljivo odabrana i homogena po strukturi. U Grčkoj robovi, 
žene i stranci nisu imali pravo građanstva. Oni su mogli da rade na agori, ali su bili formalno isključeni iz političkih aktivnosti javnog prostora. U prošlosti demokratije je mogućnost pokretljivosti, iz domena privatnog u domen javnog prostora, određivala je strukturu i kvalitet društvene i političke interakcije. Javni prostor u demokratskim zajednicama podrazumeva mogućnost napuštanja sfere privatnog, socijalizaciju i slobodu koja nije uslovljena samo privatnom svojinom nego i opštim vrednostima tolerancije i vladavine prava. Kosmopolitsko javno ponašanje postalo je u epohi prosvetiteljstva protivteža dogmatskim sferama privatnog života određenog staleškim, klasnim, polnim ili rasnim imperativima i predrasudama. Demokratizacija javnog prostora omogućila je otpor dominaciji aristokratije i klera, vezanih za ekskluzivne privatne prostore. Demokratski karakter javnog prostora podrazumevao je inkluzivnost koja je vremenom, u javnim društvenim odnosima, relativizovala staleške, klasne, ljudske ili imovinske razlike. Inkluzija i interakcija uvodile su u u javnu sferu grupe koje su dobile priliku da se bore za svoja prava i da se čuje njihovo mišljenje. [5]

Teorije urbanog razvoja ukazuju na ideje o realizaciji javnog interesa intervencionizmom zvaničnih institucija i nevladinog sektora. Ideja pametnih gradova suočava se se tekućim tendencijama urbanog razvoja koje nameće digitalizacija kompresijom i relativizacijom vremena i prostora. Virtuelni prostor nudi nove dimenzije savremenom javnom životu i kulturi. Digitalna socijalizacija je više od medijatora savremenih odnosa. Jednako je transformisan medijski prostor koji takođe nudi nove mogućnosti idejne i društvene interakcije. Nove modele tehnološke demokratizacije koriste i teoretičari urbanog planiranja.

Teorija urbanog planiranja poznata kao „Principi inteligentnog urbanizma” postavljena je na 10 aksioma - održivost životne sredine, zaštita kulturno-istorijskog nasleđa, tehnološki razvoj, efikasnost infrastrukture, uređenje urbanog prostora, javne službe, razvoj sistema javnog prevoza, regionalna integracija, ergonomija i integritet institucija. Navedeni aksiomi upućuju i na istraživanje prošlosti urbane fenomenologije koja je u izvesnim slučajevima dragocena u postupku planiranja urbane budućnosti. [6]

U slučaju Beograda, razvoj ustanova i svakodnevice zdravstvene kulture još uvek nije dovoljno istražen sa stanovišta savremenih teorija i iskustava urbanog razvoja, pre svega kao istorija prožimanja zdravstvenog sektora, zaštite životne sredine i unapređenja infrastrukture s preobražajima urbanog javnog prostora. Ostala su otvorena važna pitanja: na koji način se Beograd prilagođavao geoklimatskim uslovima, koji materijali su se koristili za izgradnju, kako je organizovan javni prevoz i na koje načine je javni prevoz ugrožavao javno zdravlje. Da li se urbanim planiranje obraćala pažnja na unapređenje socijalnih kontakata, time, posredno, i javnog zdravlja. Kakav je bio pristup čistoj vodi? S kojim se bolestima, povezanim s problemima urbanog razvoja, Beograd suočavao tokom svoje prošlosti, od XVIII veka i prvog planskog uređenja u modernom dobu do danas? Na koji način je Beograd rešavao pitanja bolesti, loše ishrane, siromaštva i one društvene nejednakosti koja je bila uzrok epidemija ili 
duševnih patnji? U kojoj meri je Beograd, tokom svoga urbanog razvoja i, ponekad, dramatičnih promena tokom od vremena prve austrijske uprave do kraja XX veka raspolagao dovoljnim znanjima, resursima i stupnjem zdravstvene kulture da bi svoj javni prostor osmišljavao i realizovao u skladu s potrebama javnog zdravlja i ostalih važnih društvenih izazova? U kojoj meri je ulagao u javno obrazovanje i razvoj profesionalnih veština? Da li bi ovakvi tematski zbornici mogli da ukažu na potrebu približavanja fundamentalnih istraživanja, teorijskih uvida i javnih politika?

\section{Reference:}

1. Ekonomska komisija za Evropu; Komisija za programsku politiku u oblasti zaštite životne sredine; Ujedinjene nacije. Pregled stanja životne sredine. Republika Srbija. Drugi pregled. Njujork i Ženeva; 2007.

2. Bjegovic V, Vukovic D, Terzic Z, Santric-Milicevic M, Laaser UT. Strategic Orientation of Public Health in Transition: An Overview of South Eastern Europe. J Public Health Policy. 2007;28(1):94-101.

3. O'Campo P, Kirst MJ, Shankardass K, Lofters A. Closing the Gap in Urban Health Inequities. J Public Health Policy. 2009;30(2):183-188.

4. Falkson JL, Plessas DJ. Toward Rationalization and Integration of Urban Health Bureaucracies. HSMHA Health Rep. 1971;86(6):495-500.

5. Mitchell D. The End of Public Space? People's Park, Definitions of the Public, and Democracy. Ann Assoc Am Geogr. 1995;85(1):108-133.

6. Caves R. urednik. Principles of Intelligent Urbanism, "Encyclopedia of the City". London: Routledge; 2004.

7. Harpham T, Pepperall J. Decentralising Urban Health Activities in Developing Countries. Dev Pract. 1994;4(2): 92-99.

8. Rosenberg E. Public Works and Public Space: Rethinking the Urban Park. Journal of Architectural Education. 1996;50(2): 89-103.

9. Talen E. Beyond the Front Porch: Regionalist Ideals in the New Urbanist Movement. J Plan Hist. 2008:20-47.

Rad primljen: 19. 8. 2014.

Recenziran: 27. 9. 2014.

Prihvaćen: 12. 10. 2014.w 